\title{
3D Technology in the Automotive Industry
}

\author{
A. S. Elakkad \\ Designs and Production Department, \\ Faculty of Engineering, Ain Shams University \\ Cairo, Egypt
}

\begin{abstract}
In today's contemporary society, the use of computer applications to enhance the process of producing or manufacturing products have become a common phenomenon. One example of such computer applications is the 3D printing software, which has been adopted by a range of corporations to optimize their manufacturing and production process. The focus of this project is on the improvement of the manufacturing technology process by use of 3D printing software in the automobile industry. The following research will cover the introduction and background of the research, description of the problem statement and analysis of literature on publications illustrating the significance of 3D technology in the automotive industry. The discussion of the research methodology used to execute the research will also be outlined, and the section will be followed by the analysis and presentation of findings of the research. Lastly, the summary of the key points of the research will be provided, and it will be accompanied by the conclusion and recommendations of the research. The findings of this study will be beneficial to the stakeholders of the automotive industry in learning how 3D printing technology can be utilized in the creation of high-quality vehicles at reduced costs.
\end{abstract}

\section{Keywords-3D, automotive industry, 3D printing, technology}

\section{INTRODUCTION}

In today's contemporary society, 3D software programs can be used as an effective intervention for optimizing the manufacturing process of vehicles in the automobiles industry. The 3D technology started in 1983 when Chuck Hull invented the first 3D printing equipment and method, which he referred to as the Stereolithography (Snyder et al., 2014). The technique involved creating solid forms by printing successive layers of ultraviolet-curable materials (Chen et al., 2019). However, it was not until about a decade later when the technology started being incorporated in creating certain parts of the manufactured vehicles. Today, 3D technology has been adopted by various automobile manufacturing companies in certain parts of the world [6]. The technology is still gradually growing in popularity today, and it is possible that all cars manufacturers in the future will, to a great extent, rely on 3D printing in enhancing their automobile manufacturing process. The phrase "3D printing" is employed to describe the series of procedures in which objects are joined or solidified by use of a computer control program to form a three-dimensional object (Al-Maliki \& Al-Maliki, 2015). Today, 3D technology is also characterized as Additive Manufacturing (AM) technology (Tofail et al. 2018). In 3D printing, people can design objects by use of computer software, to create intricate car parts that can be used for various manufacturing purposes [1]. The automotive industry is among the sectors that have largely benefited from the invention of 3D technology. It is possible to create detailed and high precise materials that refine the design and exquisiteness of certain automobile parts.
Traditionally, certain parts of cars like lamps, mirror holders, and dashboard components, in the manufacturing companies required much time and effort to be completed. In large scale car manufacturing, the designing of such parts significantly added the scale of financial and human resources needed to fully complete the automobiles for retail [2]. Nevertheless, the incorporation of the 3D technology in large scale, car manufacturing companies today have significantly reduced the overall costs of production [3]. The stated costs are those incurred through hiring teams of highly skilled professionals to create a single car part, which can be created by a single 3D machine today. The use of 3D technology has also significantly reduced the time taken to complete a single vehicle unit in the automobile manufacturing process [4]. The 3D printers have made it possible to create delicate parts of automobiles in a matter of hours [5]. Subsequently, this has reduced the overall time taken to complete the assembly of a single unit in the automobile industry [4]. It is also a phenomenon that has substantially reduced the net costs and price per unit of vehicles manufactured in the automobile industry today [3]. Subsequently, this has heightened the profitability and other revenue secured by car manufacturers that use the 3D printing technology.

Corporations that utilize 3D technology in the automobile manufacturing sector attain major competitive advantages in the market compared to their rivals. Also, that is because by using 3D printing, it is possible for the automobile manufacturing corporations to acclimatize to geometric complexity and achieve distinctive customizing ability when making unique car parts for the global market [2]. In addition, the continued use of the 3D technology has also enabled automobile manufacturers to develop prototypes and unique concept cars, which play a significant role in defining the future of automobiles and vehicle manufacturing technologies [2]. It is for this reason that there is a need for extensive research to be executed to ascertain the impact of 3D technology in revolutionizing the global automobile manufacturing industry today.

Research executed by [1] affirmed the existence of an electric car that was built using 3D printing technology. The 3D printing equipment used the ABS carbon-filter material, which was also referred to as strati, to create the parts of the electric car within 44 hours [1]. Only the electronic components such as the car battery, suspension, and motors were assembled manually. The stated case example of the electric car is a manifestation that the $3 \mathrm{D}$ printing technology can significantly reduce the time taken to manufacture a vehicle and at the same time, reduce the workforce required. Subsequently, this can translate into massive cost savings for the automobile manufacturing companies, a phenomenon that can also be reflected in the reduced retail cost of the $3 \mathrm{D}$ printing automobiles in the market. 


\section{PROBLEM STATEMENT}

The use of 3D technology in the automotive industry has been marred by a number of challenges that include the high cost of procuring the 3D technology materials, and technology limitations in manufacturing equipment (Pîrjan \& Petroşanu, 2013). Other challenges include difficulties associated to scaling operations, sufficient lack of expertise in 3D programming and regular changes in $3 \mathrm{D}$ software programs through innovation, creating the need to regularly procure new printing technology (Dwivedi, Srivastava, \& Srivastava, 2017). Nevertheless, despite such challenges, 3D technology has, to a large extent, be adopted by the automotive industry and significantly revolutionized the mode of manufacturing vehicles in today's contemporary society. Nevertheless, there is a lack of substantial published information that details the impact of 3D technology utilization in the automotive industry (Dwivedi, Srivastava, \& Srivastava, 2017). The following project will provide a detailed description of how car manufacturing corporations have benefited from the 3D software programs in optimizing their performance.

\section{LITERATURE REVIEW}

The popularity of $3 \mathrm{D}$ printing in the automotive industry has increased significantly over the past decade, and its use is still expected to grow in the oncoming financial periods. Research executed by [1], the 3D printing market in the automotive industry is expected to grow to $\$ 2391$ million by the year 2022 [1]. The growth in popularity of the 3D printing technology has been attributed to the cost-saving benefits that the technology yields to car manufacturers in creating highquality automobiles. The use of 3D technology in the automotive sector has also been supported by research executed by [6] that portrays its impact in enhancing a corporation's supply chain. According to the research, 3D printing has made it possible for car and airplane parts to be manufactured faster and efficiently, which is a phenomenon that has contributed positively to the value chain [6] Different research prepared by [7] stated that the use of 3D for printing has managed to change the paradigm for manufacturing [7]. Additionally, that is because $3 \mathrm{D}$ in the automotive industry has promoted the attainment of mass production or manufacturing in centralized factories, which have initially been constrained by tooling as well as massive low labor costs [7].

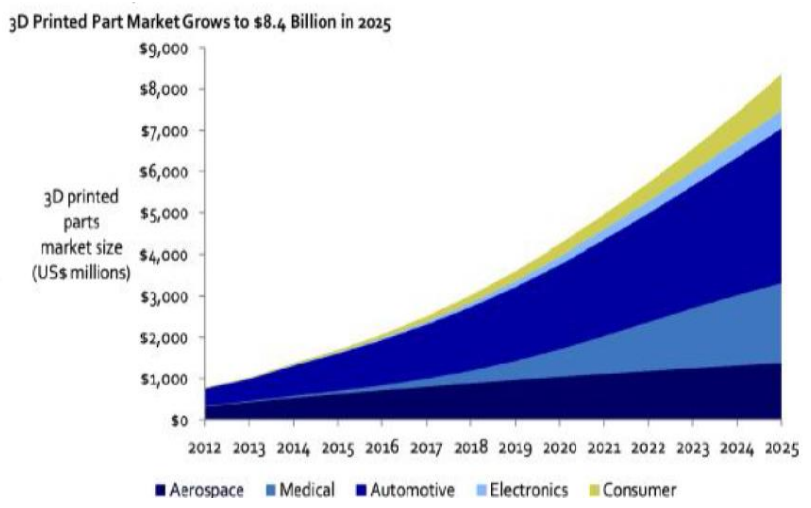

Fig. 1. Graph showing the growth in 3D technology from 2012 and the forecasted growth rate in 2025 [1].
According to [3], most of the leading automotive manufacturers have already started experimenting with the $3 \mathrm{D}$ technology in executing mass production of cars and the creation of tools and spare parts of automobiles. Also, the utilization of 3D printing technology in such car manufacturing companies has been targeted at enhancing the overall efficiency of the car manufacturing processes [3]. In different research executed by [8], 3D printing technology is already being utilized by major car manufacturers like Rolls Royce, BMW as well as Bentley, in creating strong and durable automotive parts. Over the past decade, the automotive industry has been characterized by intense competition due to the high demand for vehicles manifested in most parts of the world. According to research executed by [9], the use of additive manufacturing has been utilized as the solution for flexible production of customized products. Particularly, that is without having significant impacts on the lead time and costs incurred by car manufacturers [9]. Subsequently, this has enabled such car manufacturing companies to create high-quality vehicles at lower costs, a phenomenon that has made it possible for the organizations to compete effectively in the market.

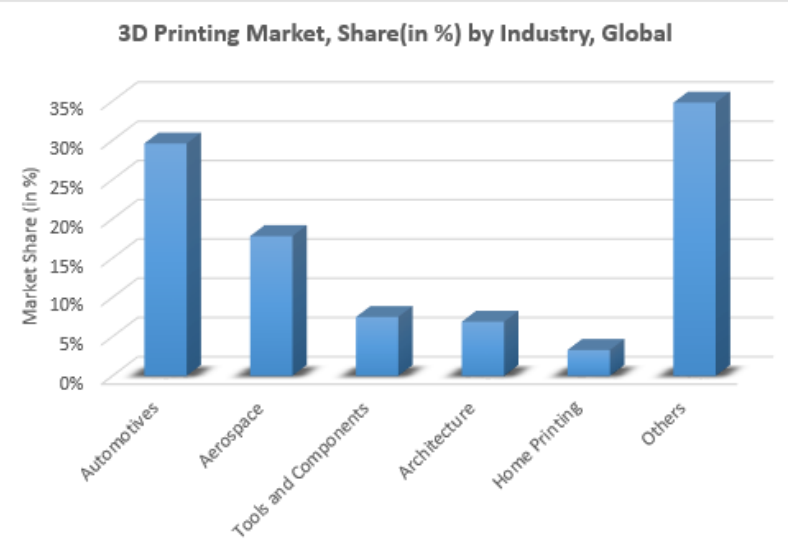

Fig. 2. Graph showing the current global market share of 3D printing technology between the automotive industry and other sectors. The graph was retrieved from the Maximize Market Research [10]

\section{RESEARCH METHOD USED AND FINDINGS} ANALYSIS

Qualitative research was performed to support the effectiveness of 3D printing technology in the automobile industry. The research executed was a survey, which was targeted at manufacturers of automobile parts at the Ford Motors, Toyota, Kia, Volkswagen, Bugatti, Mercedes, and Honda Motor corporations. The seven companies were chosen because they currently use $3 \mathrm{D}$ printing technology in their automobile manufacturing process. Also, seven respondents were issued the questionnaire survey templates with 5 structured questions focused on ascertaining the effectiveness of the 3D printers in the company's manufacturing processes. The source of the questionnaire was from the researcher who facilitated the execution of this project. The questionnaire survey featured five unstructured or open-ended questions. Moreover, the questions sought to investigate the impact of using 3D technology in promoting the automobile 
manufacturing processes. Below is a summary of the data collected after executing the research.

TABLE I. DATA SUMMARY

\begin{tabular}{|c|c|c|c|c|c|c|c|c|}
\hline $\begin{array}{l}\text { Element of } \\
\text { the } \\
\text { printers } \\
\text { researched }\end{array}$ & $\begin{array}{l}\text { Fo } \\
\text { rd }\end{array}$ & $\begin{array}{c}\text { To } \\
\text { yot } \\
\mathbf{a}\end{array}$ & $\begin{array}{c}\mathbf{K i} \\
\mathbf{a}\end{array}$ & $\begin{array}{l}\text { Vol } \\
\text { ks } \\
\text { wa } \\
\text { gen }\end{array}$ & $\begin{array}{c}\text { Bu } \\
\text { gat } \\
\text { ti }\end{array}$ & $\begin{array}{l}\text { Me } \\
\text { rce } \\
\text { des }\end{array}$ & $\begin{array}{c}\text { Ho } \\
\text { nd } \\
\text { a }\end{array}$ & $\begin{array}{l}\text { Fo } \\
\text { rd }\end{array}$ \\
\hline $\begin{array}{l}\text { Improve the } \\
\text { manufacturin } \\
g \text { cost per } \\
\text { unit }\end{array}$ & $\begin{array}{l}96 \\
\%\end{array}$ & $\begin{array}{l}98 \\
\%\end{array}$ & $\begin{array}{l}98 \\
\%\end{array}$ & $\begin{array}{l}97 \\
\%\end{array}$ & $\begin{array}{l}96 \\
\%\end{array}$ & $\begin{array}{l}99 \\
\%\end{array}$ & $\begin{array}{l}99 \\
\%\end{array}$ & $\begin{array}{l}96 \\
\%\end{array}$ \\
\hline $\begin{array}{l}\text { Allow the } \\
\text { creation of } \\
\text { geometric } \\
\text { complex } \\
\text { parts }\end{array}$ & $\begin{array}{l}99 \\
\%\end{array}$ & $\begin{array}{l}99 \\
\%\end{array}$ & $\begin{array}{l}99 \\
\%\end{array}$ & $\begin{array}{l}99 \\
\%\end{array}$ & $\begin{array}{l}99 \\
\%\end{array}$ & $\begin{array}{l}99 \\
\%\end{array}$ & $\begin{array}{l}99 \\
\%\end{array}$ & $\begin{array}{l}99 \\
\%\end{array}$ \\
\hline $\begin{array}{l}\text { Saves on cost } \\
\text { of } \\
\text { manufacturin } \\
\mathrm{g}\end{array}$ & $\begin{array}{l}95 \\
\%\end{array}$ & $\begin{array}{l}96 \\
\%\end{array}$ & $\begin{array}{l}99 \\
\%\end{array}$ & $\begin{array}{l}97 \\
\%\end{array}$ & $\begin{array}{l}96 \\
\%\end{array}$ & $\begin{array}{l}98 \\
\%\end{array}$ & $\begin{array}{l}99 \\
\%\end{array}$ & $\begin{array}{l}95 \\
\%\end{array}$ \\
\hline $\begin{array}{l}\text { Facilitates } \\
\text { customizatio } \\
\mathrm{n} \text { of } \\
\text { automobile } \\
\text { parts }\end{array}$ & $\begin{array}{l}99 \\
\%\end{array}$ & $\begin{array}{l}98 \\
\%\end{array}$ & $\begin{array}{l}94 \\
\%\end{array}$ & $\begin{array}{l}97 \\
\%\end{array}$ & $\begin{array}{l}99 \\
\%\end{array}$ & $\begin{array}{l}98 \\
\%\end{array}$ & $\begin{array}{l}96 \\
\%\end{array}$ & $\begin{array}{l}99 \\
\%\end{array}$ \\
\hline $\begin{array}{l}\text { Promoted the } \\
\text { profitability } \\
\text { and revenue } \\
\text { generation of } \\
\text { the } \\
\text { automobile } \\
\text { manufacturin } \\
\text { g companies. }\end{array}$ & $\begin{array}{l}99 \\
\%\end{array}$ & $\begin{array}{l}99 \\
\%\end{array}$ & $\begin{array}{l}99 \\
\%\end{array}$ & $\begin{array}{l}99 \\
\%\end{array}$ & $\begin{array}{l}99 \\
\%\end{array}$ & $\begin{array}{l}99 \\
\%\end{array}$ & $\begin{array}{l}99 \\
\%\end{array}$ & $\begin{array}{l}99 \\
\%\end{array}$ \\
\hline $\begin{array}{l}\text { Total/Averag } \\
\mathrm{e}\end{array}$ & $\begin{array}{l}97 . \\
6 \% \\
\end{array}$ & $\begin{array}{l}98 \\
\% \\
\end{array}$ & $\begin{array}{l}97 . \\
8 \%\end{array}$ & $\begin{array}{l}97 . \\
8 \% \\
\end{array}$ & $\begin{array}{l}97 . \\
8 \% \\
\end{array}$ & $\begin{array}{l}98 . \\
6 \%\end{array}$ & $\begin{array}{l}97 . \\
5 \%\end{array}$ & $\begin{array}{l}97 . \\
6 \%\end{array}$ \\
\hline
\end{tabular}

The responses made from the seven respondents from the seven automobile manufacturing companies were expressed as a percentage. The responses attained meant that the research participants accepted the positive impact of the $3 \mathrm{D}$ printing technology in optimizing the automobile manufacturing process. Additionally, the average data of each element of the 3D printers had a high percentage, which means that the seven companies have already benefited from the advantages of using the $3 \mathrm{D}$ printers for their manufacturing process. The attained findings illustrated that the use of the $3 \mathrm{D}$ printer decreases the cost per unit of every vehicle produced by an automobile manufacturing company. Subsequently, this decreases the price per unit of all cars manufacturing using the $3 \mathrm{D}$ technology. In addition, utilizing the 3D printing technology decreases the motor vehicle assembling companies' their cost of manufacturing. Lastly, the technology increases the net revenue and profitability of the automobile manufacturing companies in the market.

Also, a literature review method was used as the best research technique for developing research information for this project. In this case, past publications on research focused on $3 \mathrm{D}$ printing were considered for the research. In addition, the research materials used for this project were journal articles that were published within the last decade. Additionally, this was meant to promote the reliability and validity of the data obtained in compiling the findings of this project. Moreover, the use of a literature review for this project enabled the research to collect voluminous information for this project within a short time frame. Also, the gathered information was adequate for this study because it was largely a summary of the findings of other similar research performed by other researchers in the past.

The primary finding of the literature review executed has portrayed that the use of 3D technology in the automobile manufacturing sector has significantly saved the costs or expenses previous incurred by car manufacturers [1]. Subsequently, this has made it possible for car manufacturers to lower the cost of their products for customers, which is also a strategy that such entities use to combat the intense competition in the market [1]. Furthermore, research has portrayed that the use of 3D printing in research has improved the supply chain of automobile retailing corporations by increasing the number of units produced and sold to customers in the market [6]. Also, the 3D technology has made it possible for unique cars and airplane parts to be designed and manufactured faster than in the past, for customers in the market [6]. The use of 3D printing has also facilitated the attainment of mass manufacturing of vehicles and their spare parts by some automobile manufacturing corporations [7].

\section{CONCLUSION}

- In conclusion, 3D software can be used as an effective intervention for optimizing the manufacturing process of vehicles in the automobiles industry. Additionally, 3D printing originated as a technique that involved creating solid forms by printing successive layers of ultravioletcurable materials. However, today, 3D printing has largely been adopted in the automotive industry as a cost and timesaving method of developing cars. Through the use of 3D technology, certain parts of vehicles such as the lamps, mirror holders, and dashboard components, among others, can be created with ease. Furthermore, the use of 3D printing technology has helped the automobile manufacturers to optimize their supply chain and also facilitate automobile companies in securing mass manufacturing of vehicles for the available global market. Moreover, through the use of 3D printing technology, it has been possible for the automobile manufacturers to execute large scale production of spare parts for vehicles. Also, reputable car manufacturers like Rolls Royce, BMW and Bentley have adopted the 3D printing technology in the creation of strong as well as durable automotive parts. As such, it is evident that the growth in usage of $3 \mathrm{D}$ technology in most companies in the automobile industry has been massive. Also, for that reason, it is essential for all the other car manufacturers to adopt 3D technology to enhance the scale of their manufacturing operations.

\section{RECOMMENDATION}

The introduction of 3D technology in the automobile manufacturing sector has revolutionized the process of creating high-quality vehicles in the market. Today, through the use of 3D technology, it is possible for car manufacturers to design and create unique vehicle models that can satisfy the diverse tastes and preferences of customers in the market. Also, the 3D technology has made it possible for some car manufacturing corporations to compete fairly with their rivals in the market. Moreover, by using 3D technology to create vehicles, it has been possible for car manufacturers to save 
substantial costs and labor that would otherwise be incurred when using the traditional vehicle assembly designs [1]. Subsequently, this has made it possible for car creators to sell products at slightly reduced prices, which is a phenomenon that has also increased the number of car units sold to buyers in the global market.

Cumulatively, it is evident that $3 \mathrm{D}$ technology has created a range of advantages for the automobile sector today. As such, all car manufacturers should strive to adopt and incorporate 3D printing technology in their car manufacturing process. Moreover, such adoption of the 3D technology should be placed as part of the automobile manufacturer's long and short term goals [1]. In addition, it is possible that in the future, the entire automobile manufacturing sector will adopt 3D technology to solve the challenges in creating undercuts and geometric complex shapes and designs of automotive parts. Particularly, those are the parts that could be remarkably difficult to manufacture by using traditional automobile manufacturing techniques [1]. Ultimately, by comparing the featured statistical data, information provided by automobile manufacturing corporations and future scope, it is conclusive that 3D printing coupled with its technology, will revolutionize the future industrial revolution.

\section{REFERENCES}

[1] Sreehitha, V. (2017). Impact of 3D Printing in Automobile Industries. International Journal of Mechanical And Production Engineering , 5 (2), 91-94. Retrieved from http://www.iraj.in/journal/journal_file/journal_pdf/2-347149260399391-94.pd

[2] jiménez, M., Romero, L., Domínguez, I. A., Espinosa, M. d., \& Domínguez, M. (2019). Additive Manufacturing Technologies: An Overview about 3D Printing Methods and Future Prospects. Hindawi, 1-30. doi: 10.1155/2019/9656938
[3] Manghnani, R. (2015). An Exploratory Study: The impact of Additive Manufacturing on the Automobile Industry. International Journal of Current Engineering and Technology, 5 (5), 3407-3410. Retrieved from http://inpressco.com/wp-content/uploads/2015/10/Paper5634073410.pdf

[4] Ichidai, Y. (2019). Current Status of 3D Printer Use among Automotive Suppliers: Can 3D Printed-parts Replace Cast Parts? IFEAMA SPSCP, 69-82. Retrieved from http://ifeama.org/ifeamaspscp/selected\%20papers/13th\%20in\%20Ulaan baatar/13th\%2006\%20\%20Y_Ichida_final.pdf

[5] Beiderbeck, D., Deradjat, D., \& Minshall, T. (2018). The Impact of Additive Manufacturing Technologies on Industrial Spare Parts Strategies. Centre for Technology Management working paper series, 1-57. Retrieved from https://pdfs.semanticscholar.org/fde3/38bf35690594dc9a4f2822853bab 87fb45dc.pdf

[6] Mpofu, T. P., Mawere, C., \& Mukosera, M. (2012). The Impact and Application of 3D Printing. International Journal of Science and Research (IJSR), 3 (358), 2319-7064.

[7] Reeves, P., \& Mendis, D. (2015). The Current Status and Impact of 3D Printing Within the Industrial Sector: An Analysis of Six Case Studies. Centre for Intellectual Property Policy \& Management, 2015 (41), 1$15 . \quad$ Retrieved from https://assets.publishing.service.gov.uk/government/uploads/system/upl oads/attachment_data/file/549046/Study-2.pdf

[8] Sharma, A., \& Garg, H. (2016). Utility and challenges of 3 D Printing. IOSR Journal of Mechanical and Civil Engineering (IOSR-JMCE), 4953.

[9] Sarvankar, S. G., \& Yewale, S. N. (2019). Additive Manufacturing in Automotive Industry. Internationl Journal of Research in Aeronautical and Mechanical Engineering, 7 (4), 1-10

[10] Maxmize Market Research. (2019). Global 3D Printing Automotive Market and Forecast (2016-2024) by Technology, Input Materials and by Geography. Retrieved from Maxmize Market Research PVT. LTD. https://www.maximizemarketresearch.com/market-report/global-3dprinting-automotive-market/9760/ 